\section{S. N. Bose}

Professor Satyendra Nath Bose, the eminent physicist and propounder of Bose-Einstein statistics died on February 4, 1974 just as the Golden Jubilee of Bose statistics was being celebrated. He was 80 years old.

S. N. Bose was born in North Calcutta on January 1, 1894 and his interest in mathematics and the classics was kindled early in his childhood. After passing the entrance examination from the Hindu School, he joined the Presidency College where he came into close contact with eminent teachers like Sir Jagadis Bose, FRS, Sir Prafulla Ray and the principal, H. M. Percival. He obtained his MSc in 1915 in mixed mathematics along with M. N. Saha. They were both appointed the next year as lecturers in physics in the newly founded University College of Science of Calcutta. His first research publication (jointly with M. N. Saha) was $O n$ the Influence of Finite Volume of Molecules on the Equation of State followed by two papers on The Stress Equations of Equilibrium and $O n$ the Horpolhode published in the Bulletin of the Calcutta Mathematical Society. In 1920 he published his work On the Deduction of Rydberg's Law from the Quantum Theory of Spectral Emission.

During this period, Calcutta University published a booklet on relativity which contained the earliest available English translation of Einstein's papers rendered by $S$. N. Bose and M. N. Saha with a preface by P. C. Mahalanabis. Bose joined the Dacca University as a Reader in Physics in 1921. His epoch-making paper on Planck's

\section{Announcements}

\section{International Meetings}

June 25, Sixth Form Conference on Science and Technology (History and Social Science Subject Group, c/o The Admissions Office, University of Sussex, Falmer, Brighton BN1 9QH, UK).

August 4-8, 11th International Meeting of the Society for Cryobiology ( $\mathrm{Dr} \mathrm{D}$. E. Pegg, Clinical Research Centre, Watford Road, Harrow, Middlesex, HA1 3UJ, UK)

August 4-17, NATO International
Gesetz und Lichtquanten hypothese was published in Zeit für Physik, the translation into German being done by Professor Einstein himself. This paper contained the first correct treatment of the thermodynamics of the photon gas and laid the foundation of quantum statistics. His next paper, Warmegleichgewicht im Strahlungsfeld bei anwesenheit von Materie (Zeit für Physik), which he considered to be his best scientific contribution, was also translated and communicated by Einstein, but with a critical comment.

The same year he obtained two years' study leave from the Dacca University and went first to Paris where he spent some time in the laboratories of Madame Curie, Langevin, Maurice and Louis de Broglie. The following year he stayed in Berlin participating in seminars and discussions with celebrities like Planck, Schrödinger, Pauli, Heisenberg, Sommerfeld and Einstein. $\mathrm{He}$ also spent some time in the X-ray crytallography laboratory at BerlinDahlem with Polanyi.

On his return to India in 1927, he became a professor and the Head of the Department of Physics at Dacca University. In 1945 he came back to the University College of Science, Calcutta, as the Khaira Professor of Physics and held the Chairmanship of the department from 1950-56. He joined the Visva Bharati University as its ViceChancellor in 1956 and continued there until 1958. He was awarded a DSc (Honoris causa) by the Calcutta University in 1957 when it was celebrating its centenary. Later on, distinctions were showered on him by a number of universities and institutes.
In 1958 he was elected an FRS. He was the President of the National Institute of Sciences of India (1949-50) and also the General President of the Indian Science Congress Association (1944). He was a nominated member of the Rajya Sabha (the Upper House of Indian Parliament) for some time. In 1959 he became a National Professor attached to the Calcutta University and held the position until his death.

In the years following the publication of his famous paper of 1924, his research interests were many. They include his works in $\mathrm{D}^{2}$-statistics (1936), on total reflection of electromagnetic waves in the ionosphere (1938), Lorentz group (1936), on Dirac equation and Zeeman effect (1943) and on an integral equation formulation of the hydrogen atom problem (1945). His forte was a profound understanding of basic szience, which found expression in branches other than physics and research workers from varied disciplines benefited from discussions with him. During the years 1952-54 he took renewed interest in the theory of relativity.

He also made significant contributions to Einstein's unified field theory which were published in Comptes Rendus (1953), J. Phys. Radium Paris (1953) and Ann. Math. (1954), respectively.

Professor Bose was the Founder President of the Bangiya Bijnan Parishad, and of the Bengali science journal Jnan $O$ Bijnan. He was closely associated with the cultural renaissance in Bengal.

$\mathrm{He}$ leaves his wife, two sons and five daughters.
Summer School on Genetic Manipulations with Plant Material (Professor L. Ledoux, Botany Department, Université de Liège, B 4000, Liège, Belgium)

August 5-9, 7th Semi-Annual Short Course on Laser Safety (R. James Rockwell, Jr., Laser Safety Course, Conmed, 114 Medical College, Cincinnati, Ohio 45219).

August 5-24, 4th International Training Course on Membrane Biophysics (Dr Peter F. Curran, Department of Physiology, Yale University School of Medicine, New Haven, Connecticut 06510)
August 7-9, 23rd Annual Denver Conference on Applications of X-Ray Analysis (Dr C. O. Ruud, Metallurgy and Materials Science Division, Denver Research Institute, University of Denver, Denver Colorado 80210)

August 7-15, Honolulu Symposium on Population and the Family (World Population Year Secretariat, UN Fund for Population Activities, 485 Lexington Avenue, New York, New York 10017)

August 7-15, 10th International Congress of Crystallography (Tenth International Congress of Crystallography, P.O. Box 7205 Amsterdam, The Netherlands) 